\title{
EPSTEIN-BARR VIRUS-POSITIVE RECIPIENT TYPE B-CELLS SURVIVE IN A "COMPLETE CHIMERA" AFTER ALLOGENEIC BONE-MARROW TRANSPLANTATION
}

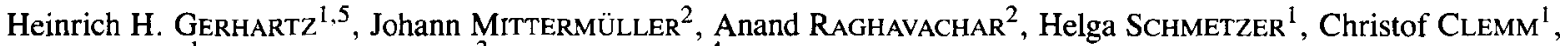 \\ Hans-J. KOLB ${ }^{1}$, Claus C. BARTRAM ${ }^{3}$ and Hans WOLF ${ }^{4}$ \\ ${ }^{1}$ Med. Klinik III, Klinikum Grosshadern, Munich University; ${ }^{2}$ Department of Transfusion Medicine, Ulm University; \\ ${ }^{3}$ Department of Pediatrics II, Ulm University; and ${ }^{4}$ Max v. Pettenkofer-Inst., Munich University, Munich, FRG.
}

\begin{abstract}
Latency of Epstein-Barr virus infection may be generated by surviving immortalized $B$ cells or by continuous re-infection. EBV-positive B-cell tumors have been found following bone-marrow transplantation (BMT) and were of donor type in the few cases investigated. We established a B-cell line from the bone marrow of a patient in complete remission following allogeneic BMT for aplastic anemia 18 months post-grafting. Differences in sex and isoenzymes allowed an exact determination of chimerism in our case. While the patient showed persistent complete chimerism of all cell lineages, cells grown in culture were of recipient type. They expressed B-cell markers, showed a monoclonal rearrangement of the immunoglobulin genes and carried EBV-associated antigens. As direct preparations of cells from the patient did not contain detectable recipient-type cells, it appeared likely that small numbers of EBV-transformed $B$ cells of the recipient survived for long periods in this patient. For the development of secondary Bcell neoplasms in vivo, additional patho-physiological steps like severe graft versus host disease or T-cell suppression are obviously required because the patient was still free of lymphoma 3 years post-grafting.
\end{abstract}

Epstein-Barr virus infection can lead in vivo to immortalized B-cell clones which are suppressed by $\mathrm{T}$-cell-mediated immunity (Rickinson et al., 1981). It is an open question whether the persistence of such B cells in vivo is the result of continuous re-infection by virus shedding from saliva (Wolf $e t$ al., 1984; Yao et al., 1985a) or of survival of low numbers of infected B cells (Yao et al., 1985b). Lymphoproliferative tumors do not usually carry EBV genomes (Andiman et al., 1983 ) but a few cases of EBV-positive lymphoma have been described following BMT (Schubach et al., 1985). These were monoclonal (Schubach et al., 1982), but polyclonal tumors have been described as well and all were of donor origin whenever this point was investigated (Martin et al., 1984). This, together with the observation that EBV-specific cytotoxic $\mathrm{T}$ cells re-emerge relatively early after allogeneic BMT (Crawford et al., 1986) argues against long-term persistence of infected B cells in vivo.

Allogeneic BMT offers an opportunity to study this problem since either sex differences between donor and recipient or genetic polymorphism of cellular isoenzymes such as AcP or PGM-1 make it possible, in most cases, to determine whether the cells in BMT patients are of donor or recipient origin (Mittermüller et al., 1986). More than $90 \%$ of European adults have been infected with EBV (Yao et al., 1985a). It is an open question whether EBV-immortalized B-cell clones of the recipient persist or whether they are eliminated either by BMT conditioning or by immunological mechanisms. We report findings which suggest that EBV-transformed clones of recipient origin can indeed persist after BMT even if the patient has become a "complete chimera" according to the most sensitive criteria that are presently available.

\section{Patient}

PATIENT AND METHODS

A 43-year-old woman presented with severe tricytopenia following nitrefazol (anti-obesity drug) complicated by bleed- ing episodes and septic complications in June 1984. A diagnosis of severe aplastic anemia was confirmed by bone-marrow biopsy and in August 1984 the patient was prepared for allogeneic BMT by cyclophosphamide i.v. ( $40 \mathrm{mg} / \mathrm{kg}$ body weigh days -5 to -2 ) plus total nodal irradiation ( $7 \mathrm{~Gy}$, day -1 ). She received $4 \times 10^{8}$ nucleated cells per $\mathrm{kg}$ body weight from her HLA-identical MLC-unreactive brother and recovered promptly with a leukocyte count of $>1 \times 10^{9} / 1$ on day 17 Post-grafting immunosuppression consisted of Cyclosporin A i.v. $5 \mathrm{mg} / \mathrm{kg}$ body weight for 5 days followed by $3 \mathrm{mg} / \mathrm{kg}$ until day 34 and subsequently orally until day 250 (9 months). No steroids were given at any time. At the time of writing, she is in full clinical remission (40 months).

\section{Cell preparation}

The patient's bone marrow cells were aspirated with preservative-free heparin after informed consent had been obtained For culture and cytogenetic studies the cells were centrifuged over Ficoll (density 1,077 g/l). For enzyme analyses the erythrocytes were sedimented and the leukocyte-rich buffy coat was further processed. Polymorphonuclear cells were isolated from the pellet of Ficoll separations by lysis of the contaminating erythrocytes with ammonium chloride. Thrombocytes were recovered from the upper layers of the buffy coat after mild sedimentation. $T$ cells and monocytes were isolated in the pellet of Ficoll-gradients by a direct immune-rosetting technique (Wilhelm et al., 1986) using erythrocytes coated with pan-T-antibodies (CD2, Rieber et al., 1986) or with antimonocyte antibodies. T-depleted lymphocytes were recovered from the interface.

\section{Morphological studies}

Smears were prepared by standard methods employing MayGrünwald-Giemsa stain, periodic acid Schiff reaction and myeloperoxidase.

\section{Immunological phenotyping}

Surface markers were identified with an enzyme-immunoassay on poly-1-lysine coated adhesive slides (Morich et al., 1983) employing polyvalent alkaline phosphatase (Sigma)-conjugated goat-anti-mouse immunoglobulin. The color reaction was performed with $0.1 \%$ naphthol-AS-MX-phosphate (Sigma)

\footnotetext{
${ }^{5}$ To whom reprint requests should be sent, at the Med. Dept. III, Klinikum Grosshadern, Marchioninistr. 15, D-8000 Munich 70, FRG.

Abbreviations: Acid phosphatase (AcP); bone-marrow transplantation (BMT); Epstein-Barr virus (EBV); EBV nuclear antigen (EBNA); graft versus host disease (GvHD); granulocyte colony-stimulating factor ( $G$ CSF); human leukocyte antigen (HLA); immunoglobulin (Ig); mixed lymphocyte culture (MLC); mononuclear cells (MNC); phosphoglucomutase-1 (PGM-1); virus capsid antigen (VCA); monclonal antibody (MAb).
}

Received: February 24, 1988 and in revised form April 12, 1988 
TABLE I - PHENOTYPE OF BMT-CHIMERA-DERIVED CELL LINE

\begin{tabular}{lccccccc}
\hline & B-1 (CD20) & B-2 (CD 19) & anti-IgM & -IgG & -IgD & -kappa & -lambda \\
\hline \% positive & 90 & 50 & 30 & 0 & 0 & 70 & 0 \\
& J5 (CD10) & OKT-9 & VIM-D5 (CD15) & VIM-2 & OKM-1 (CD14) & My4 & My7 \\
\hline \% positive & 50 & 50 & 0 & 0 & 0 & 0 & 0 \\
\hline
\end{tabular}

plus 2\% dimethylformamide (Merck), $0.1 \%$ fast red (Serva, Heidelberg, FRG) and $0.024 \%$ levamisole in 0.1 molar Trisbuffer. Each slide contained a control without primary antibody. The MAbs used were VIM-D5 and VIM-2 (CD15) which are directed against myeloid differentiation antigens, kindly provided by Dr. W. Knapp, Vienna, B-1 and B-2 (CD20, CD19) which are found on B cells and their progenitors, anti-human IgG, -IgM, anti-kappa and anti-lambda light chain antibodies as well as $\mathbf{J 5}$ (anti-common acute lymphoblastic leukemia antibody, characteristic for immature lymphoid cells) (CD 10), which were purchased from Coulter, Hialeah, FL, OKT-3 (CD3) and OKT-9 (which detects the transferrin receptor) from Ortho, Raritan, NJ. The CD-classification has been reviewed recently (Foon and Todd, 1986).

\section{Cultures}

Suspension cultures were initiated in $30-\mathrm{ml}$ flasks with $2.5 \times 10^{6} \mathrm{MNC}$ in $5 \mathrm{ml}$ Iscove-modified Dulbecco's medium supplemented with $10 \%$ fetal calf serum, $10 \%$ horse serum (both by HyClone, Logan, UT) and $5 \%$ of a supernatant of the 5637 cell line which contains G-CSF among other factors and stimulates the growth of myeloid and erythroid progenitor cells (Gerhartz and Wilmanns, 1986). All cultures were incubated at $37^{\circ} \mathrm{C}$ and $5 \% \mathrm{CO}_{2}$ in a fully humidified atmosphere and were re-fed weekly with $2.5 \mathrm{ml}$ medium plus supplements.

\section{Cytogenetics}

Karyotypic analyses were performed according to standard Giemsa-banding techniques (Seabright, 1971).

\section{Enzyme analysis}

After washing the cells with isotonic saline, freezing and thawing and ultrasonic treatment, the debris-free supernatant was analyzed. Unprocessed hair roots were typed after preincubation with Triton X 100 for $20 \mathrm{~min}$ (Mittermüller et al., 1984). PGM-1 isoenzyme analysis was performed by ultrathin isoelectric focusing on polyacrylamide gels (size $240 \times 120 \times 0.24 \mathrm{~mm}$, pH 5-6.5) (Mittermüller et al., 1985). AcP isoenzymes were determined by ultra-thin-layer isoelectric focusing in polyacrylamide gels (Burdet and Whitehead, 1977 ) with modifications (size $240 \times 120 \times 0.24 \mathrm{~mm}$, pH $3.5-$ 9.5).

\section{Western blots}

EBNA was demonstrated by Western blot analysis (Motz et al., 1986). Briefly, cell lysates were separated by SDS-polyacrylamide gel electrophoresis, transferred onto nitrocellulose filters and incubated overnight with a 1:50 diluted serum pool. Bound antibodies were detected by peroxidase-conjugated antihuman-IgG antibodies (Ortho), stained with $0.1 \% \quad \mathrm{H}_{2} \mathrm{O}_{2}$ and $0.5 \mathrm{mg} / \mathrm{ml}$ diaminobenzidine.

\section{DNA analysis}

DNA was extracted from cultured cells by standard techniques (Maniatis et al., 1982). Fifteen micrograms of DNA were digested with appropriate restriction enzymes (Boeringer, Mannheim, FRG), electrophoresed on a $0.7 \%$ agarose gel, blotted and hybridized (Raghavachar et al., 1986). To demonstrate Ig-gene rearrangements, Hind III digests were hybridized to a $1.3-\mathrm{kb}$ Eco $\mathrm{RI} \mathrm{C} \mu$ probe which detects a $17-\mathrm{kb}$ germline band (Bakhshi et al., 1983) and from Bam HI digests to a c-kappa probe which detects a $12-\mathrm{kb}$ germline band (Bakhshi et al., 1983). Both probes were kindly provided by Dr. P. Leder. After hybridization, the filters were washed under stringent conditions and exposed to XAR-5 film (Kodak) using Dupont Lightning-Plus intensifying screens for up to $24 \mathrm{hr}$ at $-70^{\circ} \mathrm{C}$.

\section{RESULTS}

\section{Cell line}

Suspension cultures of the patient's bone-marrow cells were set up 18 months post-grafting. The possibility that the culture supernatant of the 5637 cell line which was used for initial stimulation contained EBV was ruled out by previous experiments in which human cord-blood cells failed to grow continuously with this stimulator. The patient's cells decreased in number during the first 6 weeks of culture but thereafter increased continuously to about $10 \times 10^{6} \mathrm{MNC}$ per flask per week. The cells within the cultures were morphologically undifferentiated. They were negative for peroxidase and a minority of about $2 \%$ was positive for periodic acid Schiff reaction (data not shown).

\section{Immune phenotyping}

Table I shows that the cells expressed B markers (CD19, CD20, CD10) with surface IgM and kappa light chains, but no $\mathrm{T}$-cell or myeloid markers.

\section{EBV analysis}

The cells were positive for EBNA and VCA at the surface. Moreover, in a Western blot analysis of cell lysates, EBNA was clearly shown as a typical band (gel not shown). This finding supported the view that the cells in culture were immortalized by EBV.

\section{DNA analysis}

Surface marker analysis suggested that the cells were monoclonal. This was confirmed by Southern blot analysis of DNA extracted from the cell line (Fig. 1). Hybridization to $\mu$ - and kappa-specific probes clearly demonstrated a monoclonal biallelic rearrangement of both genes with no residual germ-line bands.

\section{Cytogenetic analysis}

In direct preparations of bone-marrow cells taken from the patient 11 and 19 months post-grafting, 25 and 27 metaphases were analyzed, respectively, all of which were male (Fig. $2 a$ ). Surprisingly, cells of the cultured line all had a female karyotype (Fig. $2 b$ ). The cell line, therefore, must have been derived from the recipients' B cells. This finding prompted a more detailed determination of the chimeric state using isoenzyme analyses.

\section{Acid phosphatase typing (Fig. 3)}

Figure 3 shows the results of AcP typing for all the different purified cell preparations. The recipient was heterozygous BA 


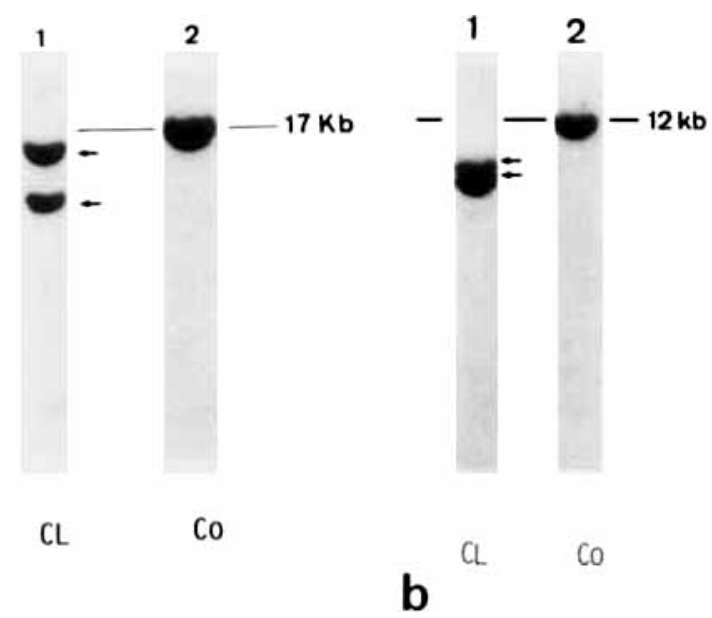

FIGURE 1 - Southern blot analysis of Ig genes. DNA of the cell line was digested with Hind III and Bam HI, electrophoresed, blotted and hybridized to a $\mathrm{c} \mu(a)$ and a c-kappa probe $(b)$. The 2 bands indicate a monoclonal biallelic rearrangement.

for AcP, showing the 3 main bands in isoelectric focusing of her hair root cells. The donor had the phenotype B comprising the 2 main bands on the gel. Following BMT all the different cell populations-erythrocytes, platelets, polymorphonuclear leukocytes, T lymphocytes, T-depleted lymphocytes, monocytes, total sedimented bone-marrow cells as well as Ficollisolated $\mathrm{MNC}$-showed the B-type bands only (Fig. 3). In contrast, the cultured cells had 3 bands, thus demonstrating the presence of the recipient type A. However, a sub-population of type-B cells could not be excluded. Therefore, corresponding investigations were made by phosphoglucomutase-1isoenzymes.

\section{Phosphoglucomutase-1 typing (Fig. 4)}

Four alleles of PGM-1 exist (a1 to a4). The patient was homozygous a1 as demonstrated by analysis of her hair root cells (erythrocytes contaminated with a2 and a3 bands via transfusions, Fig. 4). The donor cells were heterozygous a1/ a3. Following BMT, all cell lineages showed the heterozygous bands a1/a3, implying presence of donor-type cells. In contrast, the cultured cells showed the al band only, thus proving unequivocally that the cell line was of recipient origin.

\section{DISCUSSION}

Most adult individuals show immunity to EBV. The level of virus-infected $B$ cells in the blood has been shown to correspond to the level of EBV-shedding from the throat of healthy seropositive individuals (Wolf et al., 1984; Yao et al., 1985a). This, together with similar observations in immunosuppressed patients, supports the hypothesis that the EBV carrier state represents a chronic infection rather than a reactivation of "latent" EBV-immortalized clones (Yao et al., 1985b; Modrow et al., 1987). Allogeneic BMT offers an excellent opportunity to study these problems for several reasons, e.g., (a) allogeneic BMT chimeras often have markers which make it possible to determine whether the cells originate from donor or host; (b) they are, temporarily, heavily immunosuppressed and might therefore be more susceptible to reactivation of EBV-induced diseases.

However, the conditioning regimen of BMT might not only destroy the patient's own hemopoietic cells but also eliminate $B$ cells which have been immortalized by EBV. In fact, the development of secondary EBV-positive B-cell lymphomas has been only rarely observed and all cases have been of donor origin, whenever this was investigated (Schubach et al., 1982; Martin et al., 1984).

In our case, both the recipient and the donor were seropositive for EBV but did not exhibit any clinical or serological signs of reactivated infection. Nevertheless, an EBV-positive B-cell line could be grown 18 months post-grafting when the patient was off any immunosuppressive therapy and with no signs of GvHD. Differences in sex as well as in AcP and PGM-1 isoenzymes between donor and recipient enabled us to investigate the chimeric state of the transplanted patient in detail. Cytogenetic analysis may fail to identify $5-10 \%$ of different cells, but the isoenzyme methodology is independent of cell proliferation and can detect a proportion of only $1 \%$ foreign cells (Mittermüller et al., 1986). It has been repeatedly shown, by both methods, that our patient was a complete
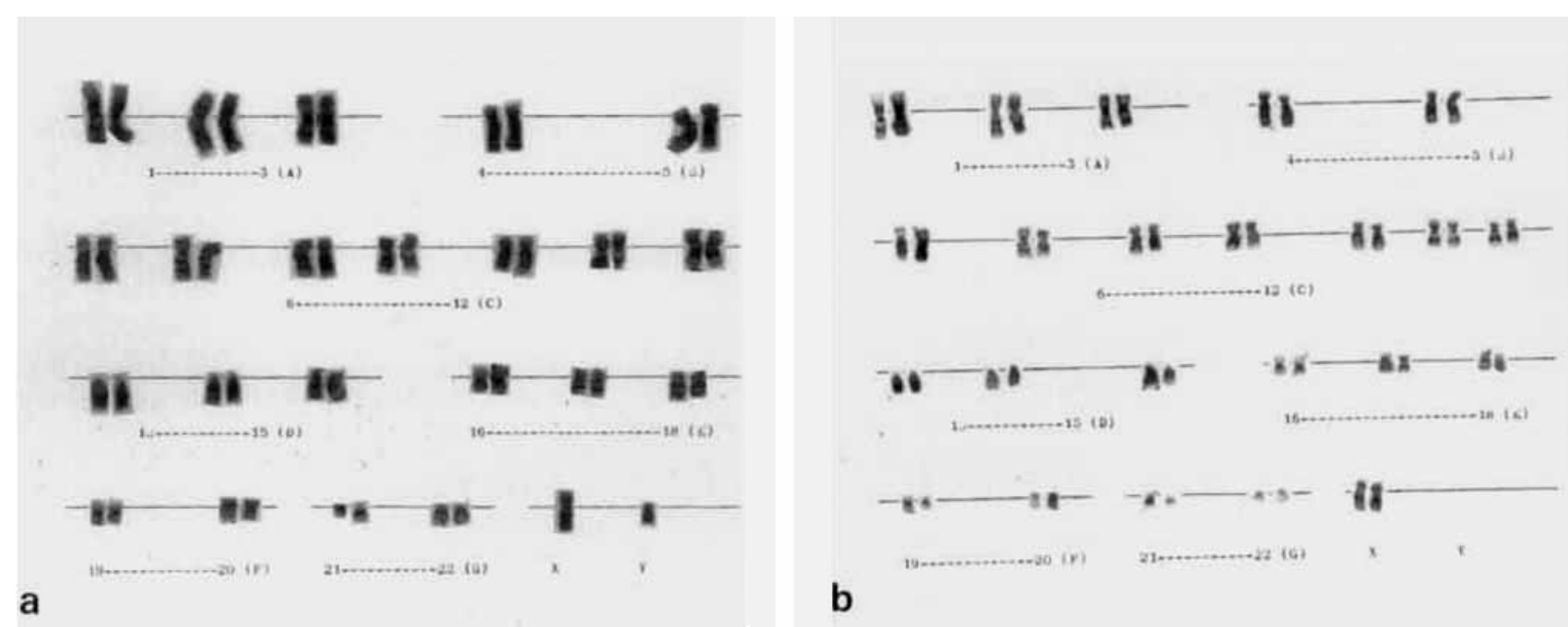

FIGURE 2 - Karyotypic analysis. Uncultured cells of the patient's bone marrow had a male karyotype (a), while that of the cell line was female 


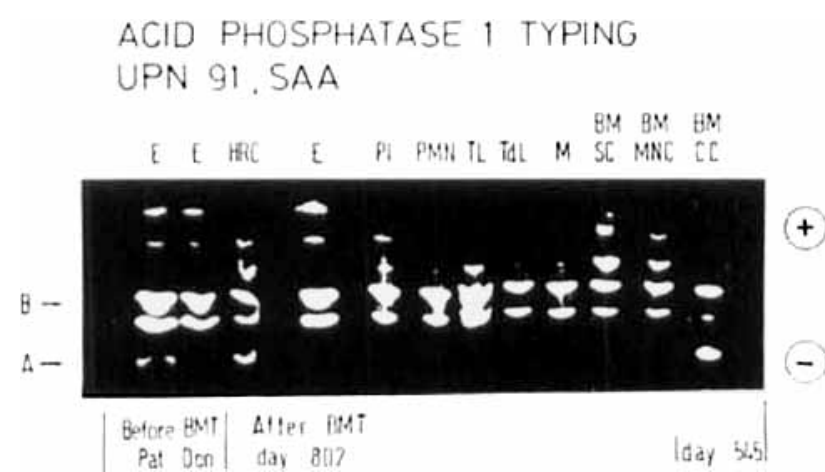

FIGURE 3 - Acid phosphatase typing. AcP isoenzymes were deter mined by isoelectric focusing. Each lane shows the bands of a different specimen: erythrocytes (E) of patient and donor before BMT, hair root cells of patient (HRC), erythrocytes of patient after BMT (E), as well as her platelets $(\mathrm{Pl})$, polymorphonuclear leukocytes (PMN), T lymphocytes (TL), T-depleted lymphocytes (TdL), monocytes (M), total sedimented BM-cells (BMSC), and Ficoll-separated BM cells (BM-MNC). The last lane shows the cell line (CC).

chimera with no detectable residual host-type cells in any of the different cell lineages (Figs. $2 a, 3$ and 4).

The cell line, however, was clearly of recipient origin (Figs. $2 b, 3$ and 4 ). Detailed analysis showed that it was an EBVpositive $B$ cell line. The possibility that the recipient-type EBV-positive cell line was a result of in vivo re-infection postgrafting cannot be entirely ruled out because the sensitivity of the method of determining the chimeric state does not exceed $1 \%$. Nevertheless, the vast excess of donor type-B cells makes it more likely that this cell line had originated from B cells which had been infected before BMT. This suggests that EBVimmortalized B cells may survive for longer periods in the human organism. Moreover, the detection of such EBV-immortalized cells shows that they may survive the conditioning regimen (high-dose cyclophosphamide plus total lymph-node irradiation).

The cell line was clearly monoclonal, as confirmed by surface markers and DNA analysis (Table I, Fig. 1). This does not necessarily indicate monoclonality in vivo since it may have been established by in vitro selection.

\section{PHOSPHOGLUCOMUTASE 1 TYPING UPN 91, SAA}

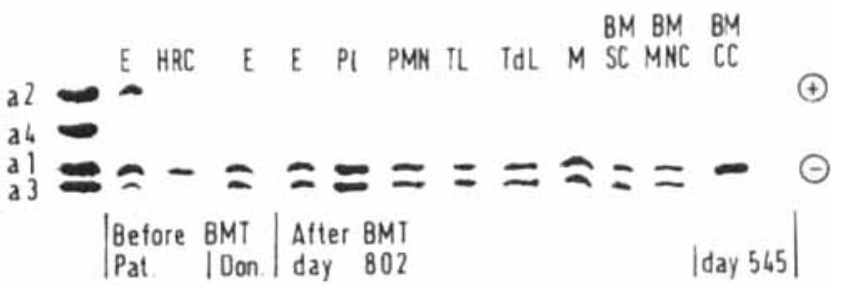

FIgURE 4 - Phosphoglucomutase-1 analysis. PGM-1 isoenzymes were detected by isoelectric focusing. Each lane presents a different specimen which follows the sequence given in Figure 3.

The contribution of the 5637-conditioned medium to the outgrowth of the cell line is unclear. Since factors produced by the cell line do not support growth of lymphoid cells (Myers et al., 1984), these might have acted--if influencing growth of the cell line at all-via stimulation of accessory cells.

Our findings suggest that recipient-derived EBV-immortalized B cells persist after allogeneic BMT in patients who appear to be "complete chimeras" even when the most sensitive methods presently available are used. One may speculate that such cells could give rise to secondary B-cell lymphomas under certain circumstances. However, our patient did not develop lymphoma within the 3 years following grafting.

\section{ACKNOWLEDGEMENTS}

We are grateful for the skillful technical assistance of Mrs. T. Mönch, Mrs. B. Hönig, Mrs. D. Knauss-Dittmann and Mrs. M. Haus. Supernatant of the 5637 cell line was a kind gift of Dr. M. Dexter, Manchester, UK. Anti-T-cell a and anti-monocyte antibodies were kindly provided by Prof. E. Rieber, Munich.

Supported by the Deutsche Forschungsgemeinschaft (SFB 324,/A9 and SFB 112/B13). H.S. is supported by the Wilhelm Sander-Stiftung, Neuburg/D. J.M. is supported by the foundation of the Medical Faculty, Munich.

\section{REFERENCES}

andiman, W., Gradoville. L., Heston, L., Neydorff, R., Savage. M.E., Kitchingman, G., Shedd, D., and Miller, G., Use of cloned probes to detect Epstein-Barr viral DNA in tissues of patients with neoplastic and lymphoproliferative diseases. J. infect. Dis., 148, 967-977 (1983).

Bakhshi, A., Minowada, J., Arnold, A., Cossman. G., Jensen, J.P., Whang-Peng. I., Waldmann. T.A., and Korsmeyer, S.J., Lymphoid blast crisis of chronic myelogenous leukemia represent stages in the development of B-cell precursors. $N$ Engl. J. Med., 309, 826-830 (1983).

Burdet, P.E., and Whttesead, P.H., The separation of the phenotypes of phosphoglucomutase, erythrocyte acid phosphatase, and some haemoglobin variants by isoelectric focusing. Anal. Biochem., 77, 419-428 (1977).

Crawford, D.H., Mulmolland, N., Iliescu, V., Hawkins, R., and Powles, R., Epstein-Barr virus infection and immunity in bone marrow recipients. Transplantation, 42, 50-54 (1986).

FOON, K.A., and TODD, R.F., Immunological classification of leukemia and lymphoma. Blood, 68, 1-31 (1986).

Gerhartz, H.H., and Wilmanns, W., Cloning of early erythroid and mixed myeloid/erythroid human bone marrow progenitor cells: comparison of different sources of burst-promoting activity (BPA). Int. J. Cell Cloning, 4, 424-431 (1986).

Maniatis, T., Fritsch, E., and Sambrock, J., Molecular cloning, a laboratory manual. Cold Spring Harbor Laboratory, New York (1982).
Martin, P.J. Shulman. H.M., Schuback. W.H., Hansen. J.A., Fefer, A., Miller. G., and Thomas, E.D., Fatal Epstein-Barr virus-associated proliferation of donor B cells after treatment of acute graft-versus-host disease with a murine anti-T-cell antibody. Ann. intern. Med., 101, 310315 (1984).

MitTermüller. J., Heim. M., and MeMPEL. W., Hair roots as control for demonstration of chimerism using PGM $_{1}$ isoenzymes. 18th Congress, Int. Society of Blood Transfusion, Munich (abstract), p. 210, S. Karger, Basel (1984).

Mittermüller, J., Kolb, H.J., Mönch, T., Clemm, C., and Gerhartz H.H., Polymorphic enzymes for investigation of chimerism and leukemic relapse after allogeneic bone marrow transplantation. Blut (abstract), $\mathbf{5 3}$ 189 (1986).

Mittermüller, J., Mönch, T., Clemm, C., and Ebell, W., Improved demonstration of chimerism after allogeneic bone marrow transplantation using ultrathin-layer isoelectric focusing of phosphaglucomutase 1. Blut (abstract), 51, 220 (1985).

Modrow. S., Jilg, W., Meerwarth, I., Majrhofer. H., Haus, M., and WOLF, H., Differential expression of EB-viral and cellular surface mark ers on Burkitt lymphoma and lymphoblastoid cells. In: P.H. Levine, D. V. Ablashi, M. Nohoyama, G.R. Pearson and R. Glasel (eds.), EBV and its diseases, pp. 407-411, Humana Press, Clifton, NJ (1987).

Morich, F.J., Momburg. F., Moldenhauer, G., Hartmann, K.U., and BRoss, K.J., Immunoperoxidase slide assay (IPSA) - a new screening 
method for hybridoma supernatants directed against cell surface antigens compared to other binding assays. Immunobiology, 164, 192-202 (1983).

Motz, M., FAN, J., SejBl, R., JlLg. W., and Wolf. H., Expression of Epstein-Barr virus 138-kDa early protein in Escherichia coli for use as antigen in diagnostic tests. Gene, 42, 303-312 (1986).

Myers. C.D., Katz, F.E., Joshi, G., and Millar. J.L., A cell line secreting stimulating factors for CFU-GEMM culture. Blood, 64, 152155 (1984).

Raghavachar, A., Bartram, C.R., Ganser, A., Heil G., Kleihauer, E., and KubaneK. B., Acute undifferentiated leukemia: implications for cellular origin and clonality suggested by analysis of surface markers and immunoglobulin gene rearrangement. Blood, 68, 658-662 (1986).

Rickinson, A.B., Moss. D.J., Wallace, L.E., Rowe, M., Misko, I.S., EPSTEIN, M.A., and POPE, J.H., Long-term T-cell-mediated immunity to Epstein-Barr virus. Cancer Res., 41, 4216-4221 (1981).

RIEBER. E.P., Human T lymphocytes. In: E.L. Reinhartz, B.F. Haynes, L.M. Nadler and I.D. Bernstein (eds.), Leucocyte typing II, p. 6, Springer, Berlin (1986)

Schubach. W.H. Hackman, R., Neiman, P.E., Miller. G., and Thomas, E.D., A monoclonal immunoblastic sarcoma in donor cells bearing Ep-
stein-Barr virus genomes following allogeneic marrow grafting for acute lymphoblastic leukemia. Blood, 60, 180-187 (1982).

Schubach, W.H., Miller. G., and Thomas, E.D., Epstein-Barr virus genomes are restricted to secondary neoplastic cells following bone marrow transplantation. Blood, 65, 535-538 (1985).

SEABRight, M., A rapid banding technique for human chromosomes. Lancet, II, $971-972$ (1971).

Wilhelm, M., Pechomer, H., Rank, G., Kopp, E., Riethmüller, G., and RIEBER, E., Direct monoclonal antibody rosetting-an effective method for weak antigen detection and large-scale separation of human mononuclear cells. J. immunol. Meth., 90, 89-96 (1986).

Wolf. H., Haus. M., and Wilmes. E., Persistence of Epstein-Barr virus in the parotid gland. $J$. Virol., 51, 795-798 (1984)

YAO. Q.Y., RiCKINSON. A.B., and EPSTEIN. M.A., A re-examination of the Epstein-Barr virus carrier state in healthy seropositive individuals. Int. J. Cancer, 35, 35-42 (1985a).

Yao, Q.Y.. Rickinson, A.B., Gaston, J.S.H., and Epstein, M.A., In vitro analysis of the Epstein-Barr virus:host balance in long-term renal allograft recipients. Int. J. Cancer, 35, 43-49 (1985b). 